\title{
ESTUDO HIGIÊNICO-SANITÁRIO DE DIFERENTES TIPOS DE IOGURTE
}

\author{
FERNANDO LEITE HOFFMANN * \\ FERNANDO CARLOS PAGNOCCA ** \\ MARIA LUÍZA SILVA FAZIO * \\ TÂNIA MARIA VINTURIM *
}

\section{INTRODUÇÃO}

O iogurte é um dos produtos alimentícios mais antigos e conhecidos, sendo também muito apreciado e consumido no Brasil. É obtido por meio de fermentação láctica do leite integral ou desnatado, concentrado ou não,

Efetuou-se levantamento das características
microbiológicas de 18 amostras de iogurte, de
diferentes sabores, comercializados e consumidos em
São José do Rio Preto (SP). Observou-se que a
maioria das amostras apresentaram elevadas
contagens de bactérias aeróbias mesófilas e
termófilas, além de baixas contagens de bactérias
aeróbias psicrotróficas, quando comparadas com os
dois tipos de contagens anteriores. Nenhuma das
amostras analisadas apresentou coliformes totais,
fecais (Escherichia coli) e Salmonella sp, sendo que
seis das amostras (33,3\%) apresentaram contagens de
Staphylococcus aureus. Treze amostras ( $72,2 \%)$
apresentaram bolores e leveduras, sendo que três
destas (23,1\%) não se enquadraram na legislação
brasileira. Concluiu-se que três amostras
apresentaram-se inadequadas para consumo de
acordo com a legislação em vigor.

* Departamento de Engenharia e Tecnologia de Alimentos, Universidade Estadual de São Paulo (UNESP), São José do Rio Preto (SP).

** Departamento de Bioquímica e Microbiologia, UNESP, Rio Claro (SP). 
pasteurizado, usando-se Lactobacillus bulgaricus e Streptococcus thermophilus ( $\mathrm{pH}$ final de 4,2-4,5). Apesar disso, o iogurte poderá apresentar microbiota bastante diversificada ligada a diversos fatores, tais como meio ambiente, qualidade das matérias-primas utilizadas e ainda processamento inadequado.

O iogurte vem passando por uma série de modificações tecnológicas desde $o$ seu aparecimento. Atualmente, levando-se em conta principalmente os hábitos alimentares e/ou as exigências dos diversos mercados, estão sendo colocados à disposição dos consumidores, novos e diferentes produtos, como molhos e temperos à base de iogurte, submetidos inclusive a tratamento térmico, visando maior vida de prateleira (BOUDIER et al., 1989). Concentrados de frutas, que quando vertidos sobre um prato ou similar, conservam a forma original do recipiente que os continham (BERGMILLER, 1987), iogurtes com adição de vinho de arroz (KAO, 1987) ou diferentes quantidades de nutrientes e até alguns com sabores raros ou exóticos, como por exemplo gerânio, flor de maçã, fruto de rosa silvestre, etc (WINWOOD, 1987). Há iogurte batido com xarope de cacau, xarope misto de cacau-cupuaçú (PINA e CLÁUDIO, 1995) e batido com polpa de frutas amazônicas como cupuaçú, taperebá e muruci (SANTOS et al., 1995). No entanto, apesar de todas as inovações técnicas, o iogurte ainda pode estar sujeito à contaminação microbiana, quando não atendidas as condições elementares de higiene e sanidade. Tal contaminação pode estar representada principalmente por leveduras (ROHM et al., 1990), psicrotróficos (JORDANO, 1988), coliformes, coliformes fecais, Staphylococcus aureus, bolores, etc (BRAZAL GARCIA et al., 1986).

No presente trabalho levantou-se as características microbiológicas de 18 amostras de iogurte comercializadas e consumidas em São José do Rio Preto (SP). Também verificou-se a qualidade higiênico-sanitária dos produtos analisados, comparando os resultados obtidos com a legislação em vigor.

\section{MATERIAL E MÉTODOS}

\subsection{OBTENÇÃO DAS AMOSTRAS}

Dezoito amostras de iogurtes, de diferentes sabores (Tabela 1), todas dentro do prazo de validade, foram obtidas em supermercado da região de São José do Rio Preto - SP. As amostras foram acondicionadas em caixas de material isotérmico (isopor), contendo cubos de gelo e transportadas de imediato ao laboratório (HARRIGAN \& Mc CANCE, 1976, ICMSF, 1978). 
Após identificação numérica as amostras foram homogeneizadas, por inversão da embalagem plástica, durante vinte e cinco vezes consecutivas. Retirou-se e colocou-se assepticamente $10 \mathrm{~mL}$ de amostra em frasco erlenmeyer, contendo $90 \mathrm{~mL}$ de água destilada estéril e homogeneizou-se (diluição $10^{-1}$ ). A partir da diluição $10^{-1}$, assim obtida, procedeu-se a diluição decimal seriada até $10^{-10}$, utilizando-se água destilada estéril como diluente. Tais diluições foram usadas na contagem de bactérias aeróbias psicrotróficas, mesófilas e termófilas, sendo somente utilizadas as diluições $10^{-1}, 10^{-2}$ e $10^{-3}$ nas análises subseqüentes (ICMSF, 1980 ).

\subsection{CONTAGEM DE BACTÉRIAS AERÓBIAS PSICROTRÓFICAS}

Utilizou-se técnica de semeadura em profundidade, empregando ágar padrão para contagem, com incubação a $7^{\circ} \mathrm{C}$ por 10 dias (ICMSF, 1978, BRASIL, 1981).

\subsection{CONTAGEM DE BACTÉRIAS AERÓBIAS MESÓFILAS}

Usou-se o método de inoculação por profundidade em ágar padrão para contagem, com incubação a $35^{\circ} \mathrm{C}$ por 48 horas (ICMSF, 1978, BRASIL, 1981).

\subsection{CONTAGEM DE BACTÉRIAS AERÓBIAS TERMÓFILAS}

Seguiu-se a técnica de semeadura em profundidade, empregando ágar padrão para contagem e incubação a $55^{\circ} \mathrm{C}$ por 48 horas (ICMSF, 1978, BRASIL, 1981).

\subsection{ENUMERAÇÃO DE BOLORES E LEVEDURAS}

Pipetou-se assepticamente $1 \mathrm{~mL}$ das diluições e distribuiu-se em placas de Petri identificadas. Adicionou-se a cada placa $15 \mathrm{~mL}$ de ágar batata dextrose acidificado com ácido tartárico a $10 \%(\mathrm{pH}=4,0)$ e homogeneizouse. Após solidificação incubou-se a $25^{\circ} \mathrm{C}$ por 5 dias. Calculou-se, de acordo com as diluições, as unidades formadoras de colônias (ICMSF, 1978). 


\section{7}

Semeou-se em duplicata, sobre a superfície do ágar telurito-gema de ovo, contido nas placas de Petri, $0,1 \mathrm{~mL}$ de cada diluição selecionada, com o auxílio de alça de Drigalsky. $O$ inóculo $(0,1 \mathrm{~mL})$ foi cuidadosamente espalhado por toda a superfície do meio até total absorção. Posteriormente, as placas de Petri foram incubadas a $37^{\circ} \mathrm{C}$ por $24-48$ horas. Calculou-se, de acordo com as diluições, as unidades formadoras de colônias.

\subsection{DETERMINAÇÃO DO NÚMERO MAIS PROVÁVEL DE COLIFORMES TOTAIS}

Foi utilizada a técnica dos tubos múltiplos, empregando caldo lauril sulfato triptose com incubação a $35^{\circ} \mathrm{C}$ durante 48 horas. O teste confirmativo foi realizado como discriminado abaixo.

\subsection{DETERMINAÇÃO DO NÚMERO MAIS PROVÁVEL DE COLIFORMES FECAIS}

Usou-se a técnica dos tubos múltiplos, empregando o caldo EC, com incubação a $44,5^{\circ} \mathrm{C}$ durante 24 horas (BRASIL, 1981). A determinação do número mais provável de coliformes totais e fecais foi realizada empregando-se a Tabela de Hoskins (ICMSF, 1978).

\subsection{PESQUISA DE Escherichia coli}

A partir dos tubos contendo caldo EC, usados na quantificação de coliformes fecais que apresentavam turvação, com ou sem gás no interior do tubo de Durham, semeou-se placas de Petri contendo ágar eosina azul de metileno. Colônias suspeitas foram identificadas utilizando-se testes bioquímicos (MARTH, 1978, SPECK, 1976). 


\subsection{PESQUISA DE Salmonella sp}

Em $225 \mathrm{~mL}$ de caldo lactosado e de água peptonada a 1\% foram homogeneizados, respectivamente $25 \mathrm{~mL}$ de cada amostra. Depois da incubação a $35^{\circ} \mathrm{C}$ por 24 horas, $1 \mathrm{~mL}$ de cada cultivo foi transferido para $10 \mathrm{~mL}$ de caldo tetrationato de Kauffmann e para $10 \mathrm{~mL}$ de caldo selenito cistina, com incubação a $35^{\circ} \mathrm{C}$. Após 24 horas, 48 horas e 5 dias foram feitas semeaduras, em placas de Petri contendo ágar SS e ágar verde brilhante, sendo as colônias suspeitas submetidas à testes bioquímicos e sorológicos (BRASIL, 1981).

\section{RESULTADOS E DISCUSSÃO}

Os resultados das análises são mostrados na Tabela 1. Apesar da legislação federal (BRASIL, 1987) não possuir padrão para este produto, no que se refere a bactérias aeróbias psicrotróficas, bactérias aeróbias mesófilas, bactérias aeróbias termófilas, Staphylococcus aureus e coliformes totais, tais análises foram realizadas para se ter uma noção da quantidade de microrganismos presentes (inclusive aqueles provavelmente utilizados no processo de fermentação láctica) e da qualidade higiênicosanitária do produto.

Os resultados das contagens de bactérias aeróbias psicrotróficas, compreendidos no intervalo de $<1$ a $1,6 \times 10^{3} \mathrm{UFC} / \mathrm{mL}$, evidenciaram que dezessete $(94,4 \%)$ das dezoito amostras analisadas apresentaram valores menores que $10^{3} / \mathrm{mL}$ obtidos por GREEN e IBE (1987), como também observou-se que dezoito amostras apresentaram resultados inferiores aos obtidos por SAAD et al. (1987) de 9,31 x 10\%3.

Não foi constatada a presença de coliformes totais, fecais (Escherichia coli) e de Salmonella $s p$ em nenhuma das amostras analisadas, apesar das amostras 1, 5, 8, 12, 13 e 17 apresentarem contagens de Staphylococcus aureus.

O resultado para coliformes ( $<3 \mathrm{NMP} / \mathrm{mL}$ ) nas dezoito amostras analisadas foi inferior aos obtidos por GREEN e IBE (1987), SAAD et al. (1987) e TAMIME et al. (1987), de respectivamente $<10 / \mathrm{mL}, 5,28 \times 10^{3} / \mathrm{g}$ e $<10$ UFC/g. Coliformes foram também encontrados em 23,3\% das amostras analisadas por JORDANO SALINAS (1986). 
TABELA 1 - REPRESENTAÇÃO DOS RESULTADOS OBTIDOS APÓS AS DIFERENTES ANÁLISES MICROBIOLÓGICAS

\begin{tabular}{|c|c|c|c|c|c|c|c|c|c|c|}
\hline $\begin{array}{c}\text { AMOSTRA } \\
\text { n. }\end{array}$ & IOGURTE & $\begin{array}{c}\text { Bactérias } \\
\text { aeróbias } \\
\text { psicrotróficas } \\
\text { (UFC/mL) }\end{array}$ & $\begin{array}{l}\text { Bactérias } \\
\text { aeróbias } \\
\text { mesófllas } \\
\text { (UFC/mL) }\end{array}$ & $\begin{array}{l}\text { Bactérias } \\
\text { aeróbias } \\
\text { termófilas } \\
\text { (UFC/mL) }\end{array}$ & $\begin{array}{c}\text { Bolores } \\
\text { e } \\
\text { leveduras } \\
\text { (UFC/mL) }\end{array}$ & $\begin{array}{c}\text { Staphylococcus } \\
\text { aureus } \\
\text { (UFC/mL) }\end{array}$ & $\begin{array}{l}\text { Coliformes } \\
\text { totais } \\
\text { (NMP/mL) }\end{array}$ & $\begin{array}{l}\text { Coliformes } \\
\text { fecais } \\
\text { (NMP/mL) }\end{array}$ & $\begin{array}{l}\text { Escherichia } \\
\text { coli } \\
\text { (confirm.) }\end{array}$ & $\begin{array}{c}\text { Salmonella } \\
s p \\
(+/-)\end{array}$ \\
\hline 1 & $\begin{array}{l}\text { Cereal e frutas } \\
\text { (mamão, maçã e } \\
\text { banana) }\end{array}$ & $1,0 \times 10^{2}$ & $2,8 \times 10^{12}$ & $3,9 \times 10^{12}$ & $<1$ & $1,0 \times 10^{1}$ & $<3$ & $<3$ & $(-)$ & $(-)$ \\
\hline 2 & $\begin{array}{l}\text { Leite de cabra - } \\
\text { sabor mel }\end{array}$ & $<1$ & $4,0 \times 10^{13}$ & $2,2 \times 10^{13}$ & $7,3 \times 10^{2}$ & $<10$ & $<3$ & $<3$ & $(-)$ & $(-)$ \\
\hline 3 & $\begin{array}{l}\text { Leite de cabra - } \\
\text { sabor morango }\end{array}$ & $<1$ & $2,2 \times 10^{13}$ & $1,1 \times 10^{13}$ & $2,4 \times 10^{6}$ & $<10$ & $<3$ & $<3$ & $(-)$ & $(-)$ \\
\hline 4 & Mel & $<1$ & $2,0 \times 10^{10}$ & $\frac{1,1 \times 10}{2,0 \times 10^{2}}$ & $1,0 \times 10^{1}$ & $<10$ & $<3$ & $\frac{3}{<3}$ & $(-)$ & $(-)$ \\
\hline 5 & Natural & $<1$ & $6,0 \times 10^{12}$ & $1,5 \times 10^{3}$ & $1,0 \times 10^{1}$ & $1,0 \times 10^{1}$ & $<3$ & $<3$ & $(-)$ & $(-)$ \\
\hline 6 & Polpa de abacaxi & $<1$ & $8,0 \times 10^{8}$ & $7,2 \times 10^{7}$ & $7,0 \times 10^{0}$ & $<10$ & $<3$ & $<3$ & $(-)$ & $(-)$ \\
\hline 7 & $\begin{array}{l}\text { Polpa de abacaxi } \\
\text { e hortelã }\end{array}$ & $<1$ & $7,8 \times 10^{9}$ & $<1$ & $<1$ & $<10$ & $<3$ & $<3$ & $(-)$ & $(-)$ \\
\hline 8 & $\begin{array}{l}\text { Polpa de acerola } \\
\text { e laranja }\end{array}$ & $<1$ & $2,4 \times 10^{13}$ & $4,4 \times 10^{12}$ & $1,0 \times 10^{0}$ & $5,0 \times 10^{1}$ & $<3$ & $<3$ & $(-)$ & $(-)$ \\
\hline 9 & Polpa de ameixa & $<1$ & $4,7 \times 10^{11}$ & $2,3 \times 10^{7}$ & $1,0 \times 10^{1}$ & $<10$ & $<3$ & $<3$ & $(-)$ & $(-)$ \\
\hline 10 & Polpa de coco & $<1$ & $5,0 \times 10^{8}$ & $6,6 \times 10^{7}$ & $2,8 \times 10^{1}$ & $<10$ & $<3$ & $<3$ & $(-)$ & $(-)$ \\
\hline 11 & $\begin{array}{l}\text { Polpa de } \\
\text { framboesa }\end{array}$ & $2,0 \times 10^{2}$ & $9,5 \times 10^{5}$ & $1,0 \times 10^{6}$ & $<1$ & $<10$ & $<3$ & $<3$ & $(-)$ & $(-)$ \\
\hline 12 & Polpa de kiwi & $1,0 \times 10^{2}$ & $\frac{1}{<}$ & $2,7 \times 10^{12}$ & $1,0 \times 10^{0}$ & $1,0 \times 10^{1}$ & $<3$ & $<3$ & $(-)$ & $(-)$ \\
\hline 13 & $\begin{array}{l}\text { Polpa de } \\
\text { morango }\end{array}$ & $<1$ & $4,6 \times 10^{8}$ & $8,6 \times 10^{8}$ & $7,1 \times 10^{3}$ & $1,0 \times 10^{1}$ & $<3$ & $<3$ & $(-)$ & $(-)$ \\
\hline 14 & $\begin{array}{l}\text { Polpa de } \\
\text { morango, } \\
\text { framboesa e } \\
\text { amora }\end{array}$ & $<1$ & $1,1 \times 10^{13}$ & $2,9 \times 10^{12}$ & $1,0 \times 10^{0}$ & $<10$ & $<3$ & $<3$ & $(-)$ & $(-)$ \\
\hline 15 & $\begin{array}{l}\text { Polpa de nozes, } \\
\text { avelãs e passas }\end{array}$ & $1,6 \times 10^{3}$ & $2,7 \times 10^{4}$ & $2,6 \times 10^{4}$ & $1,0 \times 10^{1}$ & $<10$ & $<3$ & $<3$ & $(-)$ & $(-)$ \\
\hline 16 & Polpa de pêssego & $1,0 \times 10^{2}$ & $5,2 \times 10^{8}$ & $2,5 \times 10^{8}$ & $1,2 \times 10^{5}$ & $<10$ & $<3$ & $<3$ & $(-)$ & $(-)$ \\
\hline 17 & Polpa de uva & $<1$ & $6,3 \times 10^{12}$ & $<1$ & $<1$ & $1,0 \times 10^{1}$ & $<3$ & $<3$ & $(-)$ & $(-)$ \\
\hline \multirow[t]{3}{*}{18} & $\begin{array}{l}\text { Salada de frutas } \\
\text { (pêssego, abacaxi } \\
\text { e banana) }\end{array}$ & $<1$ & $4,1 \times 10^{12}$ & $5,1 \times 10^{12}$ & $<1$ & $<10$ & $<3$ & $<3$ & $(-)$ & $(-)$ \\
\hline & Variação & $\begin{array}{c}<1 \\
a \\
1,6 \times 10^{3}\end{array}$ & $\begin{array}{c}<1 \\
a \\
4,0 \times 10^{13}\end{array}$ & $\begin{array}{c}<1 \\
a \\
2,2 \times 10^{13}\end{array}$ & $\begin{array}{c}<1 \\
a \\
2,4 \times 10^{6}\end{array}$ & $\begin{array}{c}<10 \\
a \\
5,0 \times 10^{1}\end{array}$ & $<3$ & $<3$ & $(-)$ & $(-)$ \\
\hline & $\begin{array}{l}\text { Padrão } \\
\text { Federal } \\
\text { (BRASIL, 1987) }\end{array}$ & & & & $\begin{array}{l}\text { máximo } \\
10^{3} / \mathrm{mL}\end{array}$ & & & $\begin{array}{l}\text { máximo } \\
1 / \mathrm{mL}\end{array}$ & & $\begin{array}{l}\text { ausência } \\
\text { em } \\
25 \mathrm{~mL}\end{array}$ \\
\hline
\end{tabular}


Seis das amostras analisadas (33,3\%) apresentaram resultados variando de $1,0 \times 10^{1}$ a $5,0 \times 10^{1} \mathrm{UFC} / \mathrm{mL}$, para Staphylococcus aureus, ultrapassando o resultado de <10/mL obtido por GREEN e IBE, 1987.

Já de acordo com a legislação federal (BRASIL, 1987) que estabelece para leite fermentado, com relação a coliformes fecais, o padrão máximo de 1 $\mathrm{NMP} / \mathrm{mL}$ e com relação a Salmonella $s p$, ausência em $25 \mathrm{~mL}$, todas as amostras analisadas (100\%) encontraram-se adequadas para consumo.

Com relação a bolores, o estudo realizado por SAAD et al. (1987) obteve o resultado de $8,5 \times 10^{4} / \mathrm{g}$. Bolores também foram encontrados contaminando $35,36 \%$ de iogurtes naturais e $16,67 \%$ de aromatizados (JORDANO SALINAS, 1986).

Em estudos realizados por outros pesquisadores foram encontrados para leveduras, respectivamente $>10 \mathrm{UFC} / \mathrm{g},<10 / \mathrm{g}$ a $>10^{6} / \mathrm{g}$ e $8,18 \times 10^{5} / \mathrm{g}$ (JORDANO, 1987, ROHM et al., 1990 e SAAD et al., 1987). As leveduras também foram citadas como sendo uma das maiores fontes de contaminação de iogurtes, ultrapassando o limite estabelecido para este produto em $10,63 \%$ das amostras analisadas (BRAZAL GARCIA et al., 1986).

Como a legislação federal (BRASIL, 1987) estabelece para o produto em questão, com respeito a contagem de bolores e leveduras, o padrão máximo de $10^{3} \mathrm{UFC} / \mathrm{mL}$ consideraram-se inadequadas ao consumo as amostras 3, 13 e 16 (16,7\%). A amostra 13 (iogurte com polpa de morango) foi classificada como "produto em condição higiênica insatisfatória" e as amostras 3 e 16 (respectivamente, iogurtes com leite de cabra - sabor morango e com polpa de pêssego) como "produtos impróprios para o consumo". Já as amostras 1,7,11,17 e 18, além de apresentarem as mais baixas contagens de bolores e leveduras, situandose dentro do padrão estabelecido para o produto, também enquadraram-se na legislação brasileira no que diz respeito a coliformes fecais e Salmonella sp.

As altas contagens de bolores e leveduras registradas podem ser devidas à matéria-prima de qualidade inadequada, ao meio ambiente, a existência de falhas na higienização dos equipamentos que entram em contato direto com o produto, àquelas ocorridas durante o processamento, ou ainda, a manutenção do produto em temperatura inadequada (que podem, por sua vez, acarretar produtos fora dos padrões microbiológicos recomendados, ainda na própria indústria). Recomenda-se então maior rigor na seleção de matérias-primas (de boa qualidade), o cumprimento das medidas higiênicosanitárias, inclusive na estocagem, para desta forma oferecer ao consumidor produto compatível com a legislação vigente, quer no âmbito industrial quer ao nível de comércio varejista. 
Os resultados obtidos demonstraram que, das dezoito amostras de iogurtes analisadas, três $(16,7 \%)$ encontraram-se em desacordo com a legislação brasileira em vigor. Concluiu-se que os iogurtes com polpa de morango, com leite de cabra - sabor morango e de pêssego apresentaramse inadequados para o consumo.

\begin{abstract}
A survey of the microbiological characteristics of yogurt commercialized in São José do Rio Preto, State of São Paulo, Brazil, was carried out, analyzing 18 samples with different flavors. It was observed that most samples presented high counts of thermophilic and mesophilic aerobic bacteria, besides low counts of psychrophic aerobic bacteria, when compared with the previous counts. None of the analyzed samples presented total, fecal (Escherichia coli) coliforms and Salmonella sp. Six samples (33.3\%) presented counts of Staphylococcus aureus. Thirteen samples (72.2\%) presented molds and yeasts, three of these (23.1\%) did not adjust to Brazilian legislation. The conclusion was reached that three samples proved to be inadequate for consumption according to the regulation in effect.
\end{abstract}

\title{
REFERÊNCIAS BIBLIOGRÁFICAS
}

1 BERGMILLER, M. Process and device for preparation of fruit yoghurt. German, 1987. (Federal Republic Patent Application DE 3537753 A 1).

2 BOUDIER, J.F., COLIN, J.Y., SOTTIEZ, P. Yoghurt-based sauces and their manufacture. France, 1989. (French Patent Application FR 2623376 A 1).

3 BRASIL. Ministério da Saúde. Portaria n. 001 de 28 de janeiro de 1987. Aprova padrões microbiológicos para alimentos. Diário Oficial [da República Federativa do Brasil], Brasília, 25 fev. 1987.

4 BRAZAL GARCIA, T., RUIZ-ATIENA RUIZ, L., ESPEJO DIAZ, M. Microbiological quality of natural and flavoured yoghurts, consumed in Alicante Province. Alimentaria, v. 177, p. 39-42, 1986.

5 GREEN, M.D., IBE, S.N. Yeasts as primary contaminants in yogurts produced commercially in Lagos, Nigeria. Journal of Food Protection, v. 50, n. 3, p. 193-198, 205, 1987.

6 HARRIGAN, W.F., MC CANCE, M.E. Laboratory methods in food dairy microbiology. London: Academic Press, 1976. 353 p. 
INTERNATIONAL COMMISSION ON MICROBIOLOGICAL SPECIFICATIONS FOR FOODS. Microorganisms in foods: their significance and methods of enumeration. 2. ed. Toronto : University of Toronto Press, 1978. v.1

INTERNATIONAL COMMISSION ON MICROBIOLOGICAL SPECIFICATIONS FOR FOODS. Microbial ecology of foods. New York : Academic Press, 1980. v. 2

9 JORDANO, R. Relationship between airborne contamination by yeasts and moulds and packaging system in commercial yoghurt. Microbiologie Aliments Nutrition, v. 5, n. 3, p. 253-255, 1987.

10 JORDANO, R. Incidence and evolution of psychrotrophic bacteria in commercial yoghurt kept in cold storage. Microbiologie Aliments Nutrition, v. 6, n. 4, p. 407-409, 1988.

11 JORDANO SALINAS, R. Hygienic quality of commercial yoghurts. Alimentaria, v. 178, p. 27-30, 1986.

$12 \mathrm{KAO}, \mathrm{H}$. Preparing naturally sweet yoghurt with Saccharomycopsis spp and Rhizopus spp. United States, 1987. (Patent, US 4714616).

13 MARTH, E.E. Standard methods for the examination of dairy products. $14 \mathrm{ed}$. Washington: APHA, 1978. $416 \mathrm{p}$.

14 BRASIL. Ministério da Agricultura. Métodos analíticos oficiais para controle de produtos de origem animal e seus ingredientes. Brasília, 1981.

15 PINA, M.G.M.P., CLÁUDIO, C.R. Elaboração de iogurte batido com xarope de cacau (Theobroma cacao L) e xarope misto cacaucupuaçú (Theobroma grandiflorum, shum ). In: CONGRESSO NACIONAL DE LATICÍNIOS, 13., 1995. Anais... [Juiz de Fora] : CEPE - ILCT - EPAMIG, 1995. p. 65-68

16 ROHM, H., LECHNER, F., LEHNER, M. Microflora of austrian natural-set yogurt. Journal of Food Protection, v. 53, n. 6, p. 478-480, 1990.

17 SAAD, N.M., MOUSTAFA, M.K., AHMED, A.A.H. Microbiological quality of yoghurt produced in Assiut city. Assiut Veterinary Medical Journal, v. 19, n. 37, p. 87-91, 1987. 
18 SANTOS, V.J.R.M., SOUZA, O.S.V.A., CAMPOS, E.M.A., ROBERTS, K.W.W., MACHADO, S.R.E.S., NEVES, E.C.A. Elaboração de iogurte batido com polpa de frutas amazônicas: parte I: cupuaçú, taperebá e muruci. In: CONGRESSO NACIONAL DE LATICÍNIOS, 13., 1995. Anais... [Juiz de Fora] : CEPE - ILCT - EPAMIG, 1995. p. $69-72$

19 SPECK, M.L. Compendium of methods for the microbiological examination of foods. [Washington] : APHA, 1976. $702 \mathrm{p}$.

20 TAMIME, A.Y., DAVIES, G., HAMILTON, M.P. The quality of yoghurt on retail sale in Ayrshire. I. Chemical and microbiological evaluation. Dairy Industries International, v. 52, n. 6, p. 19-21, 1987.

21 WINWOOD, J. The living world of yoghurt. Food Manufacture, v. 62, n. 6, p. 39, 41 e 43, 1987. 